\title{
Evidence of the Participation of Peribiliary Mast Cells in Regulation of the Peribiliary Vascular Plexus Along the Intrahepatic Biliary Tree
}

\author{
Wataru Koda, Kenichi Harada, Koichi Tsuneyama, Naoko Kono, Motoko Sasaki, \\ Osamu Matsui, and Yasuni Nakanuma
}

Departments of Pathology (II) (WK, KH, KT, NK, MS, YN) and Radiology (WK, OM), Kanazawa University School of Medicine, Kanazawa, Japan

\begin{abstract}
SUMMARY: Our pilot study disclosed that tryptase-positive mast cells (MC) were densely distributed around the intrahepatic bile ducts (peribiliary MC). In this study, the pathophysiologic roles of these MC were examined with respect to the microcirculation around the bile duct in 71 cases of histologically normal liver, 24 cases of chronic hepatitis, and 45 cases of liver cirrhosis. The tryptase-positive MC were very close to the microvessels of the peribiliary vascular plexus (PVP), which supply the intrahepatic biliary tree. The tryptase-positive MC were frequently found adjacent to vascular smooth muscle cells, including pericytes. The location of the tryptase-positive MC was confirmed by ultrastructural analysis. In cirrhosis, the numbers of both microvessels of PVP and peribiliary MC increased in parallel. Peribiliary MC were immunoreactive for endothelin 1 (ET-1), and were variably immunoreactive for histamine, chymase, inducible nitric oxide synthase (iNOS), and endothelin $A$ and $B\left(E T_{A}\right.$ and $\left.E T_{B}\right)$ receptors, particularly in cirrhotic livers. On vascular endothelial cells of PVP, endothelial nitric oxide synthase (eNOS) and ET-1 were consistently detectable, and $\mathrm{ET}_{\mathrm{A}}$ receptors, $\mathrm{ET}_{\mathrm{B}}$ receptors, and $\mathrm{iNOS}$ were variably detectable. Pericytes of $\mathrm{PVP}_{\mathrm{P}}$ expressed $\mathrm{ET}_{\mathrm{A}}$ and $E T_{B}$ receptors in addition to ET-1 and iNOS. Biliary epithelial cells also focally expressed iNOS, $E T-1$, and $E T_{A}$ and $E T_{B}$ receptors. These vasoactive substances were strongly expressed on the cellular components in cirrhotic liver. By in situ hybridization, iNOS mRNA signals were observed on iNOS-immunoreactive cell components, including peribiliary MC. These morphologic and immunohistochemical findings suggest that the cellular components displaying vasoactive substances in the milieu of the intrahepatic biliary tree are very dynamic in the vasoregulation of PVP in normal livers, even more so in cirrhosis, and that peribiliary MC exert local effects on the microcirculation of PVP, directly and indirectly. A list of abbreviations: AMeX, acetone, methyl benzoate, and xylene; ASMA, $\alpha$-smooth muscle actin; $\mathrm{ET}$, endothelin; $\mathrm{ET}$-1, endothelin 1; $\mathrm{ET}_{\mathrm{A}}$ receptor, endothelin $\mathrm{A}$ receptor; $\mathrm{ET}_{\mathrm{B}}$ receptor, endothelin $\mathrm{B}$ receptor; eNOS, endothelial nitric oxide synthase; $\mathrm{MC}$, mast cell; $\mathrm{MC}^{\top}$, tryptase positive, chymase negative mast cells; MC ${ }^{\mathrm{TC}}$, tryptase positive, chymase positive mast cells; NO, nitric oxide; iNOS, inducible nitric oxide synthase; PBS, phosphate buffer saline; PVP, peribiliary vascular plexus; TNF-, tumor necrosis factor $\alpha$ (Lab Invest 2000, 80:1007-1017).
\end{abstract}

\begin{abstract}
$M$ ast cells (MC) are concentrated within the mucosa of several organs such as the respiratory and gastrointestinal tract (Galli, 1993; Irani et al, 1989; Weidner and Austen, 1990, 1991). By virtue of the release of the large number of preformed and newly formed biologic active substances, MC have a great potential to influence mucosal functions such as ion transport of mucosal epithelium (Crowe et al, 1997). $\mathrm{MC}$ are also being actively studied in several organs from the standpoint of microcirculation. For example, the role of $\mathrm{MC}$ in the regulation of gastric mucosal blood flow was reported by Wallace et al (1992). Feldman et al (1996) disclosed that the hyperemic response of the esophageal mucosa to capsaicin was attenuated by the MC stabilizer doxantrazole. Additionally, $\mathrm{MC}$ are also involved in the synthesis of nitric oxide (NO) in endothelial cells. The number of MC is
\end{abstract}

Received January 18, 2000.

Address reprint requests to: Dr. Y. Nakanuma, Department of Pathology (II), Kanazawa University School of Medicine, Kanazawa 920-8640, Japan. Fax: 076234 4229; E-mail: pbcpsc@kenroku.kanazawa-u.ac.jp known to increase in inflammatory diseases such as psoriasis and in hypervascular tumors, eg, glioblastoma, and these MC play an important role in the angiogenesis and regulation of blood flow in the lesions. It has been also disclosed that angiotensin II produced by chymase released from MC not only contracts but takes part in the remodeling of blood vessels (Sayama et al, 1987).

Most studies of intrahepatic microcirculation have focused on hepatic sinusoid and small portal tracts, and emphasized the importance of pericytes around terminal portal venules and perisinusoidal cells, particularly their importance to the microcirculation in hepatic lobules and to endothelial/perisinusoidal cell interactions with respect to effector molecules such as endothelin (ET) and NO. However, little is known about the hemodynamic regulation of the peribiliary vascular plexus (PVP) that develops around the intrahepatic biliary tree.

Recently, we noticed a hitherto undescribed dense and regular distribution of $\mathrm{MC}$ beneath the biliary epithelia of the intrahepatic large bile ducts (Ya- 
mashiro et al, 1998). These MC may participate in the process of bile duct fibrosis (Farrell et al, 1995; Yamashiro et al, 1998). However, their role in the regulation of in situ blood flow of the intrahepatic biliary tree have not been elucidated.

In this study, we analyzed the exact distribution of $\mathrm{MC}$ along the intrahepatic biliary tree by tryptase, a specific and sensitive marker of MC (Farrell et al, 1995; Walls et al, 1990) immunoreactivity. We then clarified the role of the $\mathrm{MC}$ with respect to the microcirculation around the intrahepatic biliary tree by examining the immunoreactivity and in situ hybridization (ISH) of vasoactive substances. In cirrhotic livers, the small vessels of PVP are known to increase and dilate, and are believed to reflect altered intrahepatic hemodynamics (Kobayashi et al, 1994).

\section{Results}

\section{Distribution of Peribiliary MC in Normal and Cirrhotic Livers}

Distribution of Tryptase-Positive MC. MC were strongly immunoreactive for human MC tryptase. The tryptase-positive MC were regularly and densely distributed along the septal and intrahepatic large bile ducts (Fig. 1A) and around intrahepatic peribiliary

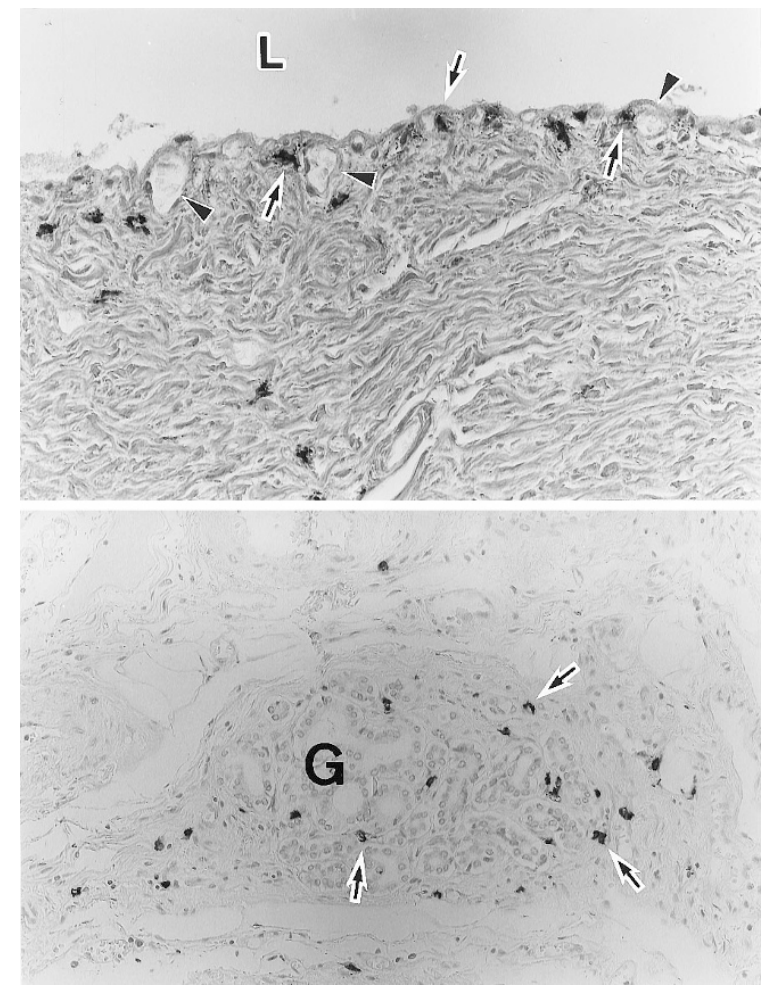

Figure 1.

A. Tryptase-positive mast cells (MC) (arrows) are densely distributed beneath the lumen of the intrahepatic large bile duct, particularly adjacent to the capillaries (arrow heads) of peribiliary vascular plexus (PVP). Biliary lining epithelia are artificially dropped. L: bile duct lumen. Normal liver. Immunoreactivity of tryptase and hematoxylin counterstaining. Original magnification, $\times 300$. B. Tryptase-positive MC (arrows) are densely distributed within and around the peribiliary glands $(G)$. Normal liver. Immunoreactivity of tryptase and hematoxylin counterstaining. Original magnification, $\times 200$. glands (Fig. 1B). They are referred to as peribiliary MC in this study. Peribiliary MC were dense and regular under the biliary lining epithelia, although they were rather scattered in the ductal walls and periductal tissue. MC were also scattered around the interlobular bile ducts and bile ductules. In other parts of the liver, MC were not constantly present, except for a considerable number beneath the hepatic capsule.

In cirrhotic livers, peribiliary MC were gathered in the duct wall, in periductal tissue, and beneath the biliary lining cells. MC were also concentrated around the peribiliary glands in cirrhotic livers. The number of MC around the septal bile ducts in cirrhotic livers (59.0 $\left.\pm 29.9 / \mathrm{mm}^{2}\right)$ was significantly increased, when compared with normal livers $\left(39.4 \pm 20.8 / \mathrm{mm}^{2}\right)(p<$ $0.001)$. The number of peribiliary $M C$ in chronic hepatitis $\left(46.6 \pm 28.3 / \mathrm{mm}^{2}\right)$ was between numbers found in normal and cirrhotic livers.

\section{Relation Between MC and PVP}

The majority of peribiliary MC beneath the biliary epithelia were close to small vessels, including capillaries of the inner layer of PVP in normal and cirrhotic livers (Fig. 1). Double-immunoreactivity of tryptase and $\alpha$-smooth muscle actin (ASMA) showed that approximately half of the peribiliary $M C$ were directly adjacent to ASMA-immunoreactive pericytes or vascular smooth muscle cells in these vessels, in both normal and cirrhotic livers (Fig. 2). The close topologic relation between $\mathrm{MC}$ and capillaries of PVP was also shown ultrastructurally (Fig. 3). A quantitative study using sections immunoreactive for tryptase and CD34 disclosed a numerical association between the peribiliary MC and the vessels of PVP in normal and/or cirrhotic livers ( $r=0.713)$ (Fig. 4).

\section{Immunohistochemistry of Vasoactive Substances in Microenvironments Around the Intrahepatic Bile Duct}

Nitric Oxide Synthase (NOS). Endothelial nitric oxide synthase (eNOS) was detectable on endothelial cells of PVP in normal livers, and its expression was increased on cells of the increased and dilated PVP in cirrhotic livers (Table 1). eNOS was not detectable in other cellular and tissue elements. With doubleimmunohistochemistry for eNOS and CD34, the majority of vascular endothelial cells were immunoreactive for both eNOS and CD34, although some cells were immunoreactive for just the synthase or CD34 in cirrhotic liver.

Inducible nitric oxide synthase (iNOS) was absent or only faintly demonstrable on endothelial cells and pericytes of PVP in normal livers, although it was more clearly and extensively expressed on endothelial cells and pericytes of PVP and smooth muscle cells of hepatic arteries and portal veins in cirrhotic livers. Additionally, iNOS extensively expressed at low levels on biliary epithelial cells of septal bile ducts and intrahepatic large bile ducts and peribiliary glands in normal and cirrhotic livers. Double-immunoreactivity for iNOS and ASMA and for iNOS and CD34 revealed 
Table 1. Immunohistochemical Expression of Vasoactive Mediators in the Milieu of the Intrahepatic Large Bile Duct and Septal Bile Duct in Normal and Cirrhotic Livers

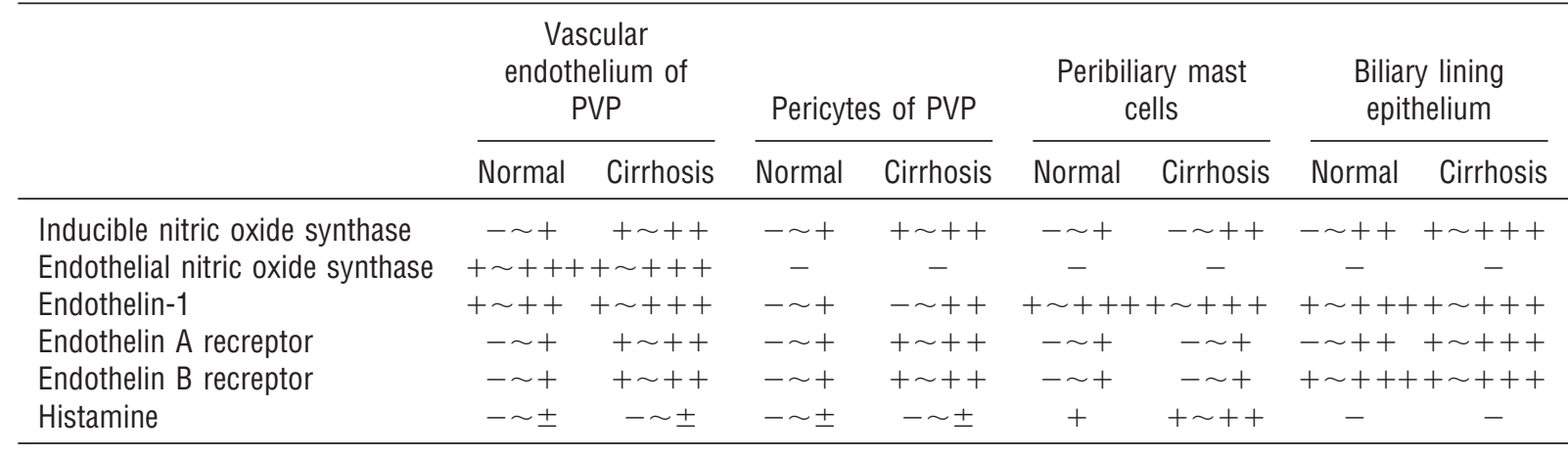

PVP, peribiliary vascular plexus; - , negative expression; \pm , questionable staining; + , focal and weak expression; ++ , between + and $+++;+++$, diffuse and strong expression.

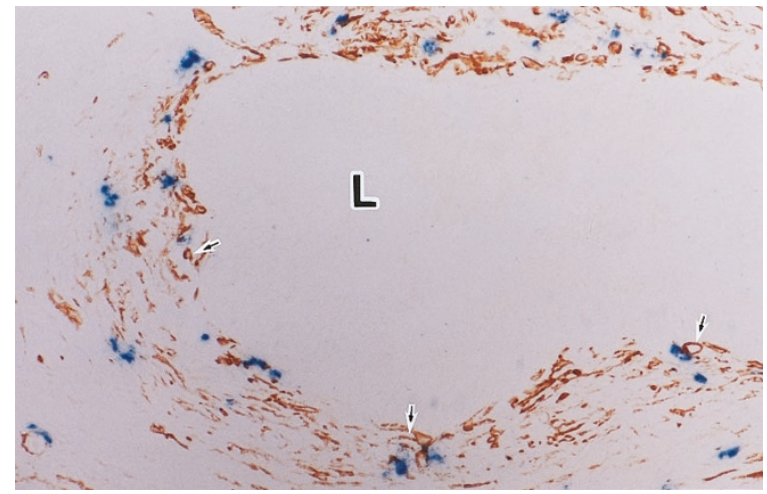

\section{Figure 2.}

Tryptase-positive MC (blue) are seen around the $\alpha$-smooth muscle actin (ASMA)-immunoreactive smooth muscle or pericytes (brown) of PVP. Brown immunoreactive cells other than PVP are myofibroblasts in the bile duct wall. Bile duct lining epithelia are artificially dropped. Liver cirrhosis. Doubleimmunoreactivity of ASMA (brown) and tryptase (blue). Original magnification, $\times 200$.

iNOS expression on these anatomical elements (Fig. 5, A and B). Double-immunoreactivity for iNOS and tryptase disclosed that peribiliary $\mathrm{MC}$ in normal and cirrhotic livers were immunoreactive for iNOS (Fig. 6A), and both the number and proportion of $\mathrm{MC}$ expressing iNOS increased in cirrhotic livers. ISH revealed that iNOS mRNA was also present on the cell components that were immunoreactive for each protein (Fig. 7). The semi-quantitative study showed an increased proportion of iNOS-immunoreactive MC in cirrhotic liver (Table 1).

$E T-1$ and $E T_{A}$ and $E T_{B}$ Receptors. ET-1 was detectable in peribiliary $\mathrm{MC}$, biliary lining epithelia, and peribiliary glands, in addition to endothelial cells and pericytes and smooth muscle cells of PVP in normal and in cirrhotic livers, respectively (Fig. 6B). The proportion, number, and immunoreactive intensity of ET-1-expressing cell components including peribiliary $\mathrm{MC}$ were increased in cirrhotic compared with normal livers (Table 1). Additionally, double-immunohistochemistry clearly showed that $\mathrm{ET}_{\mathrm{A}}$ and $E \mathrm{~T}_{\mathrm{B}}$ receptors were present on endothelial cells, pericytes or smooth muscle cells of PVP and hepatic arterial branches and portal veins,

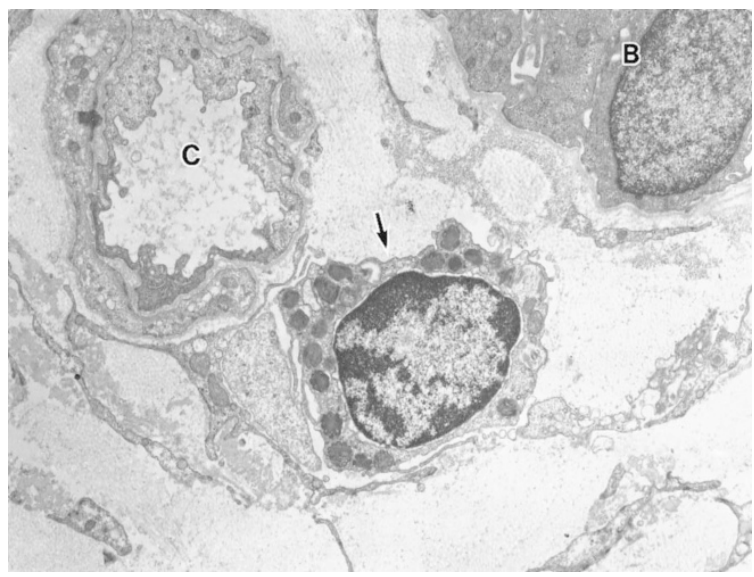

Figure 3.

MC close to capillary $(C)$ of the PVP. MC contains many granules in its cytoplasm. Normal liver. Electron microscopic observation. B: bile duct epithelial cells. Original magnification, $\times 9,500$.

biliary epithelial cells of septal bile ducts, intrahepatic large bile ducts and peribiliary glands, and also some peribiliary MC (Fig. 8, A and B).

\section{Histamine}

Histamine was detectable in some peribiliary MC. In this study, faint immunoreactivity for histamine was also identified on the basement membrane of peribiliary glands and bile ducts.

\section{Chymase}

The ratios of chymase-positive $M C$ to tryptasepositive MC were approximately $0.49 \pm 0.24$ in normal liver and $0.96 \pm 0.36$ in cirrhotic liver $(p<0.01)$ (Fig. 9 ). Approximately half of the peribiliary MC located beneath the biliary lining epithelia and around the peribiliary glands in normal livers were $\mathrm{MC}^{\top}$ (tryptasepositive, chymase-negative $\mathrm{MC}$ ), while half were $\mathrm{MC}^{\mathrm{TC}}$ (tryptase-positive, chymase-positive MC). The majority of peribiliary $\mathrm{MC}$, including those beneath the biliary lining epithelia and ductal walls in cirrhotic livers, were of $\mathrm{MC}^{\mathrm{TC}}$ type. The wide variation in the 


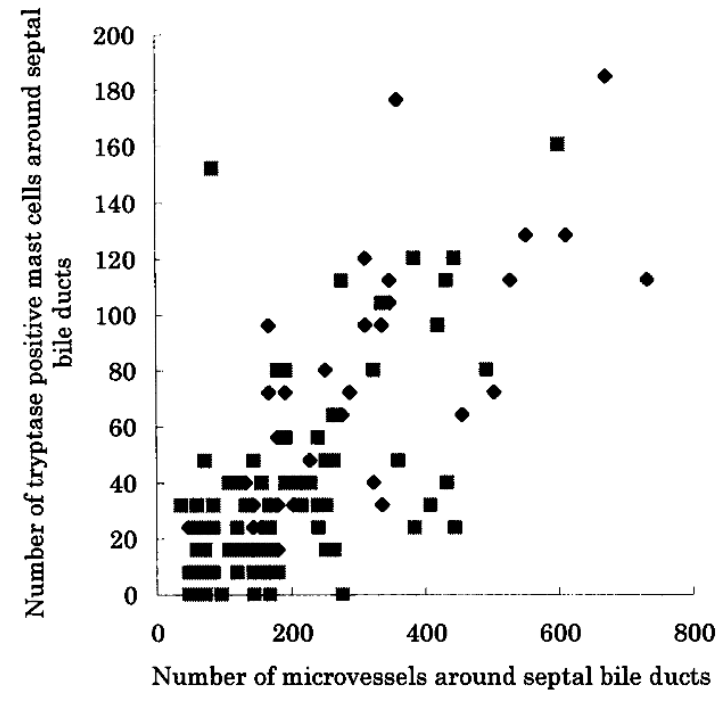

Figure 4.

The correlation among the number of microvessel PVP and the number of peribiliary MC. These two elements are correlated in number in normal and/or cirrhotic livers. $r=0.713$, normal liver; cirrhotic liver.

ratio was due to the different liver tissues used for tryptase and chymase, chymase being only detectable with acetone, methyl benzoate, and xylene (AMeX) fixation.

\section{Discussion}

The dense and regular distribution of $\mathrm{MC}$ around the intrahepatic large bile duct and septal bile duct suggests that the $\mathrm{MC}$ are a constitutive cell population (peribiliary $\mathrm{MC}$ ) of the intrahepatic biliary tree and are involved in the regulation of the functions of intrahepatic biliary tree such as in situ defense and bile flow. This distribution pattern of peribiliary MC is reminiscent of that of $\mathrm{MC}$ in the mucosa of the gastrointestinal and respiratory systems (Galli, 1993; Irani et al, 1989; Weidner and Austen, 1990, 1991). Interestingly, most MC beneath the biliary epithelia were close to the small vessels, including capillaries of the inner layer of PVP in normal and cirrhotic livers. In fact, double-immunoreactivity disclosed that approximately half of these MC were directly adjacent to ASMA-immunoreactive pericytes or vascular smooth muscle cells of PVP. The close association of pericytes and MC was also clear ultrastructurally. The number of peribiliary MC and the vessels of PVP was increased in cirrhotic livers. This increase of peribiliary MC may reflect an adaptive response of the intrahepatic biliary tree in the cirrhotic liver.

Advanced liver disease, irrespective of etiology, is associated with a hyperdynamic circulation characterized by systemic vasodilation and increased cardiac output (Abelmann, 1991). In normal and diseased livers, the hemodynamic regulation in the hepatic lobules is mainly conducted by perisinusoidal cells and endothelial cells by releasing ET and NO as effector molecules (Gondo et al, 1993; Leivas et al, 1998, Rockey et al, 1998). Regarding the hemody- namics around the intrahepatic biliary tree, the endothelium of PVP may take part in the regulation of vascular tone through the release of relaxing and contracting factors under basal conditions, and when activated by different stimuli, as has been speculated for other organs (Laffi and Marra, 1999; Luscher et al, 1993). The close topologic and numeric association of the peribiliary $M C$ and the small vessels of PVP suggests that the peribiliary MC participate directly or indirectly in the regulation of these vessels by an autocrine and/or paracrine effect. In other organs, such as the esophagus and stomach, the regulatory roles of $\mathrm{MC}$ in the microcirculation are well known (Feldman et al, 1996; Wallace et al, 1992). To investigate how peribiliary $M C$ might be involved in the hemodynamic regulation of PVP, we examined the expression of vasoactive substances in the tissues.

$\mathrm{NO}$ is a strong and important vasodilator (Martini et al, 1996). We found that eNOS was constantly expressed on endothelial cells of PVP in normal livers, and that this expression was increased in PVP of cirrhotic livers. Although iNOS was not expressed or faintly expressed on endothelial cells of PVP in normal livers, iNOS was more clearly and extensively expressed on endothelial cells and pericytes of PVP in cirrhotic livers. The numbers and proportions of $\mathrm{MC}$ expressing iNOS were increased in cirrhotic livers, although only a few peribiliary $\mathrm{MC}$ in normal livers were immunoreactive for iNOS. The expression of iNOS was stronger and more widespread in the bile duct epithelium and peribiliary glands in cirrhotic livers, compared with normal livers. iNOS has a ten-fold greater rate of NO production than eNOS (Lewis et al, 1995; Reilly et al, 1983). Increases in the expression of iNOS and eNOS are followed by the release and diffusion of NO (Lancaster, 1994), which affects vascular smooth muscle tone (Schmidt and Walter, 1994), resulting in vascular dilation followed by hyperdynamic circulation in cirrhosis (Schrier et al, 1988; Sogni et al, 1995). Blood vessels of PVP are increased in number and dilated in cirrhosis (Kobayashi et al, 1994), probably reflecting peripheral vasodilation and hyperdynamics in cirrhosis (Michielsen and Pelckmans, 1994). The small vasculatures of PVP are markedly increased and rather dilated in cirrhotic livers (Kobayashi et al, 1994). Recent experimental data point to a role for an increased production of the locally acting potent endothelial-independent and endothelial-dependent vasodilators, particularly excessive synthesis of $\mathrm{NO}$ in the vascular wall, in the pathogenesis of the hyperdynamic circulation (LopezTalavera et al, 1996). The increased expression of NOS in the microenvironments of the biliary tree in cirrhosis found in this study may be responsible for the changes of PVP, particularly in cirrhosis. The increased blood flow through the MC-derived histamine- and NO-dependent system was welldocumented as contributing to the mucosal defense in the other regions of the gastrointestinal tract (Feldman et al, 1996). This may also be the case in the intrahepatic biliary tree. 
Table 2. Main Clinical Features of the Patients and Their Liver Specimens

\begin{tabular}{lccccc}
\hline & Sex & Age $(\bar{X} \pm S D$, & \multicolumn{3}{c}{ Liver specimens } \\
\cline { 4 - 6 } & (F:M) & years) & Autopsy & Surgical resection & Wedge biopsy \\
\hline Normal liver (71) & $28: 43$ & $62.9 \pm 16.2$ & 60 & 1 & 10 \\
Chronic hepatitis (24) & $14: 10$ & $64.9 \pm 13.0$ & 11 & 1 & 12 \\
Liver cirrhosis (45) & $17: 28$ & $62.7 \pm 11.1$ & 42 & 0 & 3 \\
\hline
\end{tabular}

(), number of cases examined; F, female; $M$, male.

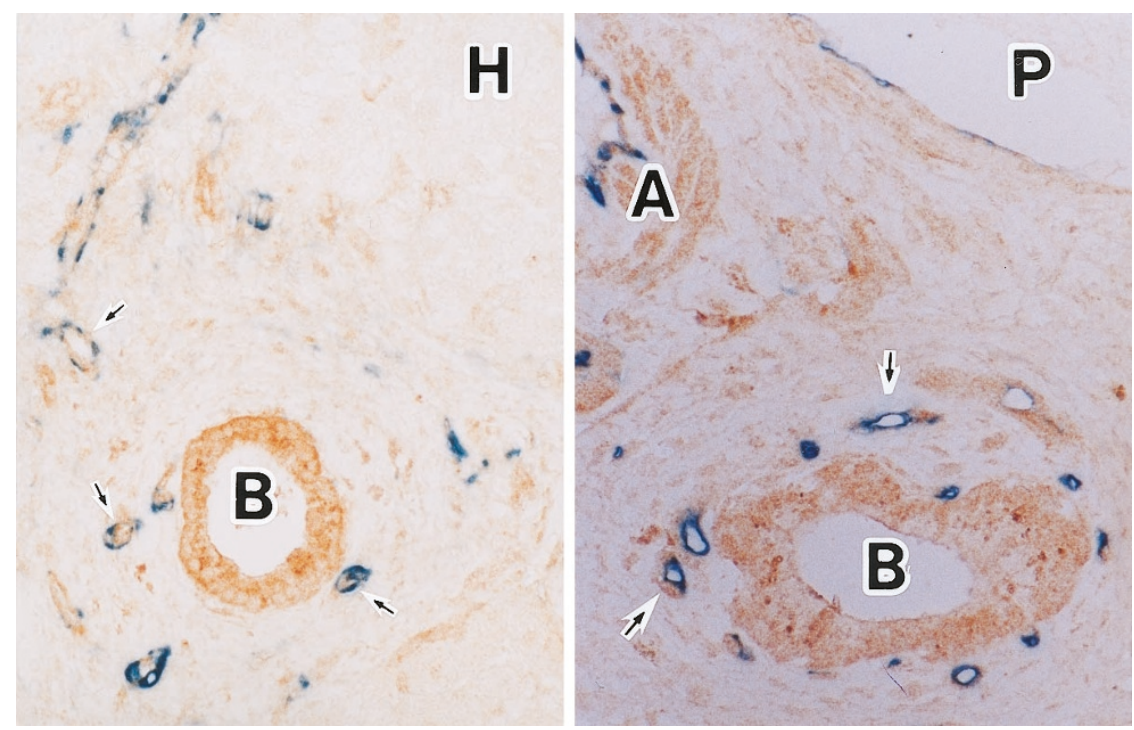

\section{Figure 5 .}

A. Inducible nitric oxide synthase (brown) is demonstrable on the septal bile duct $(B)$ and endothelial cells of PVP (arrows). Pericytes or smooth muscle cells of PVP are immunoreactive for ASMA (dark blue). $\mathrm{H}$ : hepatic parenchyma. Liver cirrhosis. Double-immunoreactivity of inducible nitric oxide synthase (brown) and ASMA (blue). Original magnification, $\times 150$. B. Inducible nitric oxide synthase (brown) is demonstrable on the septal bile duct $(B)$, the endothelial cells of PVP (arrows), on the portal vein $(P)$, and on the smooth muscle of the hepatic arterial branch $(A)$. Endothelial cells of PVP, portal vein, and hepatic arterial branch are immunoreactive for CD34. Liver cirrhosis. Double-immunoreactivity of inducible nitric oxide synthase (brown) and CD34 (blue). Original magnification, $\times 150$.

The major function of ET-1 is the local control of vascular tone by constriction of smooth muscle cells of vessels (Yanagisawa, 1994), by its preferential binding to $\mathrm{ET}_{\mathrm{A}}$ receptor. In the liver, ET-1 is a potent vasoconstrictor, acting at both sinusoidal and extrasinusoidal sites, via autocrine or paracrine effects (Bauer et al, 1994; Leivas et al, 1998; Rockey et al, 1998). We found that ET-1 was detectable in almost all peribiliary MC, biliary lining epithelia, and peribiliary glands, in addition to endothelial cells and pericytes and smooth muscle cells of PVP in normal and cirrhotic livers. The proportion, number, and intensity of ET-1-expressing cell components were increased in cirrhotic livers compared with normal livers. Additionally, $\mathrm{ET}_{\mathrm{A}}$ and $\mathrm{ET}_{\mathrm{B}}$ receptors were detectable on endothelial cells and pericytes of PVP, biliary epithelial cells, and also some MC. Expression of ET-1 protein and its mRNA on intrahepatic biliary epithelial cells is reported in cirrhotic livers (Pinzani et al, 1996), and secretion of ET-1 was shown in primary cultures of human gallbladder epithelial cells (Housset et al, 1993). The actions of ET1 at the site of synthesis are of great importance to physiologic regulation and pathologic development (Gandhi et al, 1996). Thus, ET-1 produced in the milieu of the intrahepatic biliary tree may play a role in the constriction of small vasculatures of PVP by affecting pericytes and smooth muscle cells via an autocrine and paracrine effect. In this context, the peribiliary MC that express ET-1 would also be involved in the vasoregulation of PVP.

Histamine, a potent vasodilator, increases vascular permeability (Befus et al, 1988). Feldman et al (1996) disclosed that, in the esophagus, MC-derived histamine, acting through an NO-dependent mechanism, plays a central role in the vasodilating response to luminal acid of the esophageal microcirculation, and the resultant esophageal hyperemia protects the esophageal mucosa. A part of the peribiliary MC population was immunoreactive for histamine in normal and cirrhotic livers in this study. Histamine released from peribiliary MC may be directly operative on vessels or may act indirectly by inducing eNOS from endothelial cells (Shibayama, 1998). The histamine immunoreactivity of the basement membrane of peribiliary glands and bile ducts suggests that histamine is retained in the basement membrane.

Chymase acts on vascular smooth muscle cells as a vasoconstrictor (Sayama et al, 1987). It is also known to be an angiotensin II-generating enzyme, able to increase blood pressure and to induce proliferation of 

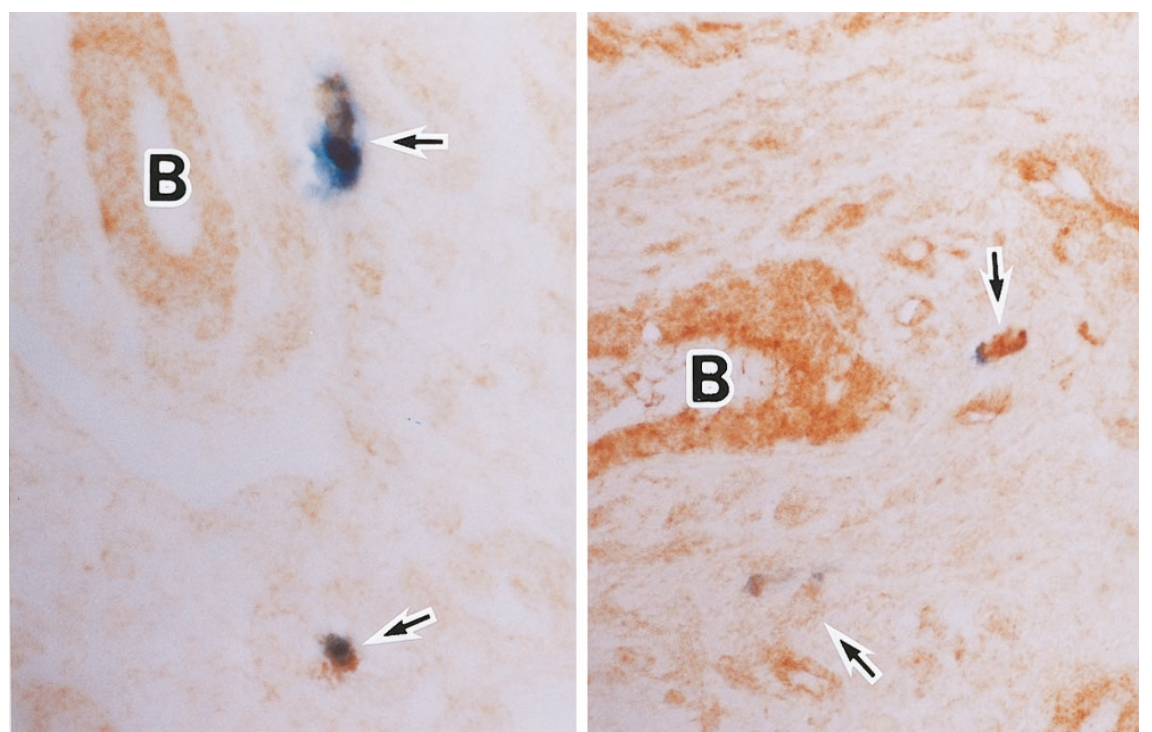

\section{Figure 6 .}

A. Double-immunoreactivity of inducible nitric oxide synthase and tryptase. Septal bile duct $(B)$ and endothelial cells of PVP are immunoreactive for inducible nitric oxide synthase. Peribiliary MC (arrows) are immunoreactive for inducible nitric oxide (brown) and tryptase (blue). Liver cirrhosis. Original magnification, $\times 200$. B. Double-immunoreactivity of endothelin 1 and tryptase. Two peribiliary MC are double-immunoreactive (bluish dark brown) for endothelin 1 (brown) and tryptase (blue). Septal bile duct $(B)$ is immunoreactive for endothelin-1. Liver cirrhosis. Original magnification, $\times 150$.

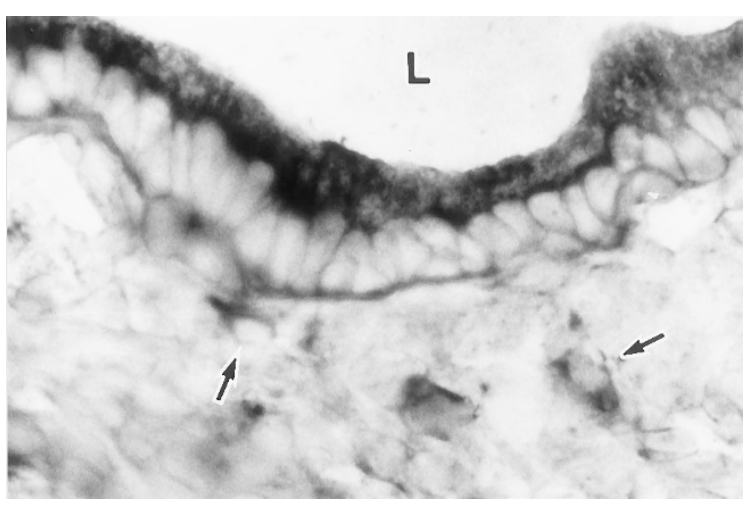

Figure 7.

In situ hybridization disclosed that signals of mRNA of inducible nitric oxide synthase are present in the biliary epithelial cytoplasm of the intrahepatic large bile duct and on the peribiliary MC (arrows). The location of these MC beneath the biliary epithelial layer makes these cells identifiable. L: bile duct lumen. Nuclei are clearly spared in this immunoreactivity. Liver cirrhosis. Original magnification, $\times 400$.

vascular smooth muscle cells (Okunishi et al, 1984). lin the present study, approximately half of peribiliary MC were $\mathrm{MC}^{\top}$ in normal livers, although the majority of peribiliary $\mathrm{MC}$ in cirrhotic livers were $\mathrm{MC}^{\mathrm{TC}}$. This result suggests that peribiliary MC in cirrhotic livers are able to secrete more chymase than those in normal livers. Chymase secreted from peribiliary MC is likely to be involved in altering the hemodynamics around the biliary tree in cirrhotic livers.

The expression levels of vasoactive substances in several cellular components around the bile ducts in normal and cirrhotic livers are shown in Table 1. The presumed effects of these substances on PVP and other cellular components are schematically summarized in Figure 10. It should be mentioned that the number and proportion of peribiliary MC expressing these vasoactive substances are increased in cirrhotic livers. As for the mechanisms or substances that influence and regulate the peribiliary MC, tumor necrosis factor $\alpha$ and interleukin 1, together with lipopolysaccharides, which are increased in circulation in cirrhosis (Vallance and Moncada, 1991), may be responsible for the upregulated expression of iNOS on MC (Morris and Billian, 1994). Additionally, MCderived substances, such as histamine (Sogni et al, 1997), may be responsible for the increase in expression of iNOS (Alexander, 1998). In this context, the peribiliary $\mathrm{MC}$ may play a role in the dilation of small vessels of PVP and thereby increase the blood flow of PVP, by directly expressing iNOS and indirectly inducing NOS expression in other peribiliary cell elements. Foreman (1987) proposed that the $\mathrm{MC} /$ nerve unit is involved in a series of physiologic events such as the regulation of local blood flow and that neurotransmitters that are released from peripheral nerves by axon reflexes influence histamine secretion by MC. Recently, Akiyoshi and Terada (1998) reported that nerve fibers are closely located to $\mathrm{MC}$ in the liver. Uchida et al (1992) reported that ET-1 is also known to stimulate MC, followed by the release of bioactive substances. The present study immunohistochemically detected $E T_{A}$ and $E T_{B}$ receptors on $M C$, supporting Uchida et al (1992). Substance $P$, which is produced in the liver, may also induce degranulation of MC (Suzuki et al, 1995). Taken together, it seems very likely that the peribiliary $\mathrm{MC}$ are, at least in part, controlled by hepatic autonomic nerve fibers and by humoral factors locally released in the liver or arriving at the liver. Recently, biliary epithelial cells were reported to express stem cell factor (Omori et al, 1997), which is able to activate and accumulate MC. A more detailed and 

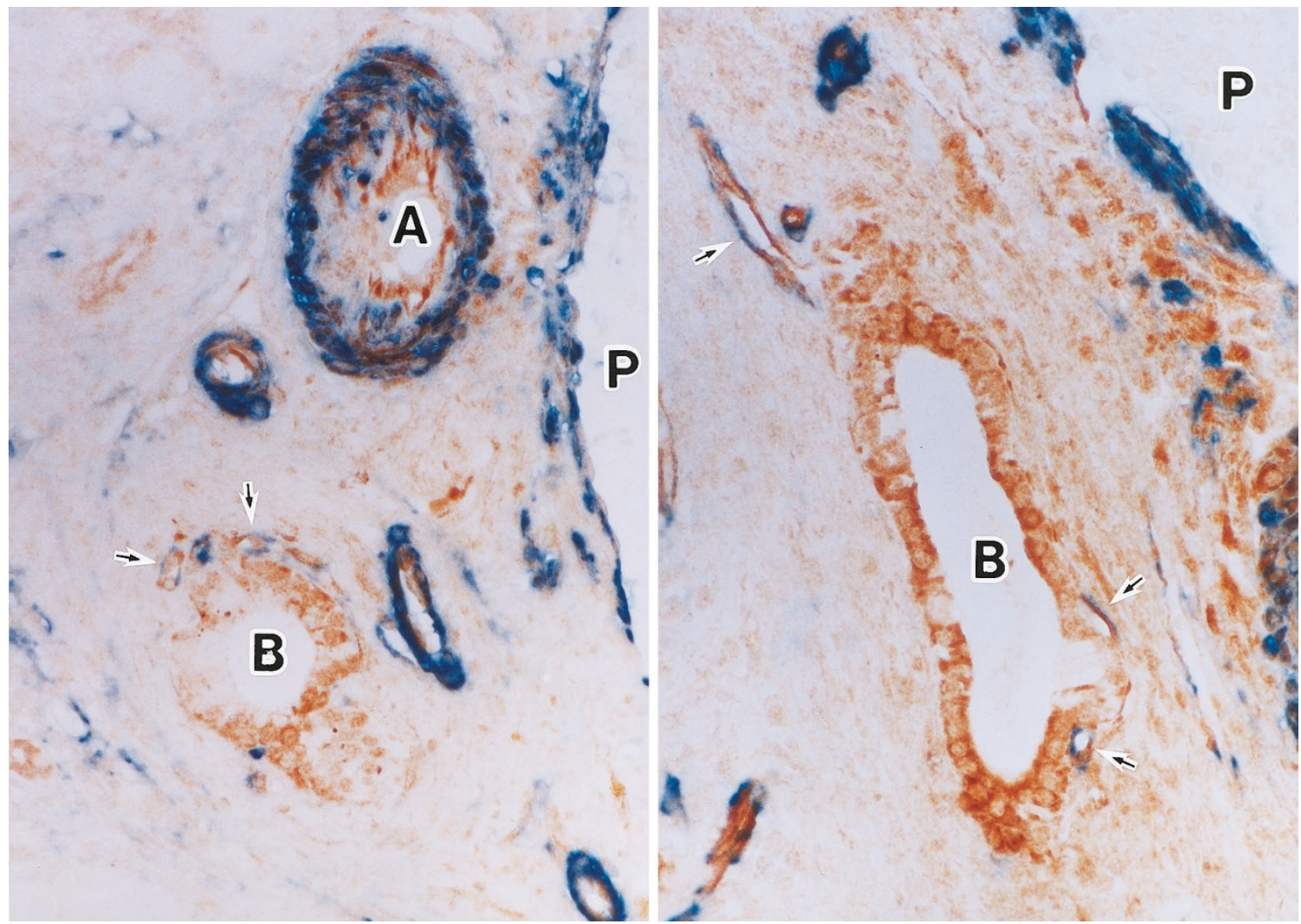

\section{Figure 8.}

A. Double-immunoreactivity of endothelin A receptor (brown) and ASMA (blue). Endothelial cells of PVP, hepatic arterial branches $(A)$, portal vein $(P)$, and biliary epithelial cells of septal bile duct $(B)$ are immunoreactive for endothelin A receptor (brown). Smooth muscle or pericytes of PVP (arrows) and hepatic arterial branches and portal veins are immunoreactive for ASMA (blue). Liver cirrhosis. Original magnification, $\times 200$. B. Double-immunoreactivity of endothelin B receptor and ASMA (blue). Vascular endothelial cells, pericytes of PVP (arrows), and biliary epithelial cells of septal bile duct (B) are immunoreactive for endothelin B receptor (brown). Smooth muscle or pericytes of PVP and hepatic arterial branches (arrows) and portal veins $(P)$ are immunoreactive for ASMA (blue). Liver cirrhosis. Original magnification, $\times 200$.

comprehensive analysis of peribiliary MC using human diseases and animal models may give new insights into the complex networks regulating PVP in normal livers and various hepatobiliary diseases.

In conclusion, $\mathrm{MC}$, in addition to other cellular elements in the milieu of the intrahepatic large bile duct and septal bile ducts, express and probably secrete vasoactive substances such as NOS, ET, chymase, and histamine. These vasoactive substances may, in turn, exert paracrine and autocrine effects on the endothelial cells or surrounding pericytes and vascular smooth muscle cells of PVP, locally influencing the hemodynamics of PVP and the physiology of the intrahepatic biliary tree in normal and cirrhotic livers.

\section{Materials and Methods}

\section{Classification of Intrahepatic Biliary Tree and PVP}

Intrahepatic Biliary Tree. The intrahepatic biliary tree was classified into the right and left hepatic duct, segmental duct (the first major branches of each hepatic duct), area duct (the first major branches of each segmental duct: anterior and inferior area ducts of each segmental duct), and their finer branches

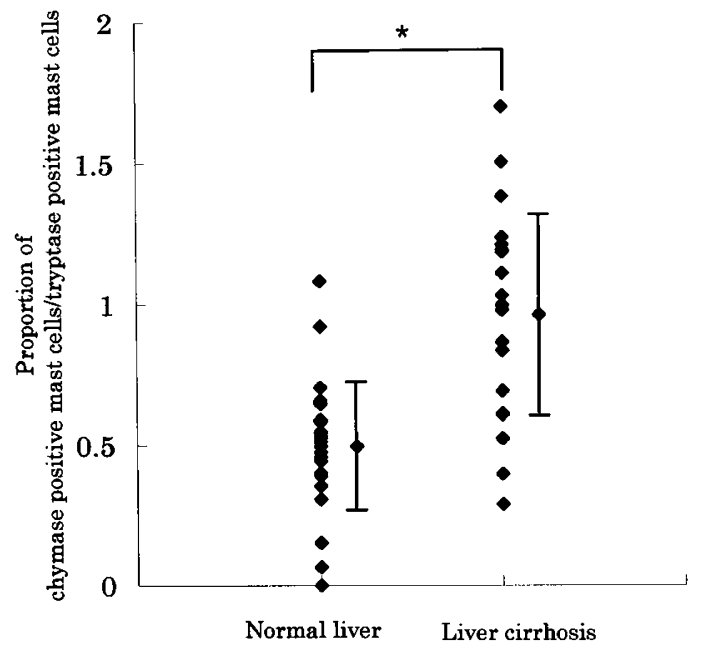

Figure 9.

Proportion of MC expressing chymase and tryptase. The ratio of chymasepositive MC to tryptase-positive MC was approximately $0.49 \pm 0.24$ in normal liver, although the ratio was $0.96 \pm 0.36$ in liver cirrhosis $(p<0.01)$.

(Nakanuma et al, 1997). The hepatic, segment, and area ducts and their first branches are collectively termed intrahepatic large bile ducts, which are visible 
Table 3. Antibodies Used in this Study

\begin{tabular}{|c|c|c|c|c|}
\hline Antibodies used & Source & $\begin{array}{l}\text { Animals } \\
\text { immunized }\end{array}$ & $\begin{array}{c}\text { Type of } \\
\text { antibodies }\end{array}$ & $\begin{array}{l}\text { Optimal } \\
\text { dilution }\end{array}$ \\
\hline \multicolumn{5}{|l|}{ Primary antibodies against } \\
\hline CD34 & IMMUNOTECH, Marceille, France & mouse & Monoclonal & $1: 200$ \\
\hline Mast cell tryptase, $\mathrm{AA} 1$ & DAKO, Glostrup, Denmark & mouse & Monoclonal & $1: 200$ \\
\hline Mast cell chymase & BIOGENESIS, England, United Kingdom & mouse & Monoclonal & $1: 5000$ \\
\hline Histamine & ICN Pharmaceuticals, Aurora, Ohio & rabbit & Polyclonal & $1: 200$ \\
\hline Endothelin-1 & AFFINITY BIOREAGENTS, Golden, Colorado & mouse & Monoclonal & $1: 500$ \\
\hline Endothelin A Receptor & ALEXIS, San Diego, California & sheep & Polyclonal & $1: 400$ \\
\hline Endothelin B Receptor & ALEXIS, San Diego, California & sheep & Polyclonal & $1: 40$ \\
\hline $\begin{array}{l}\text { Inducible Nitric Oxide } \\
\text { Synthase }\end{array}$ & AFFINITY BIOREAGENTS, Golden, Colorado & rabbit & Polyclonal & $1: 500$ \\
\hline $\begin{array}{l}\text { Endothelial Nitric Oxide } \\
\text { Synthase }\end{array}$ & $\begin{array}{l}\text { TRANSDUCTION LABORATORIES, Lexington, } \\
\text { Kentucky }\end{array}$ & mouse & Monoclonal & $1: 200$ \\
\hline \multicolumn{5}{|c|}{ Biotinylated secondary antibodies } \\
\hline against Sheep IgG & Vector Laboratories, Burlingame, California & rabbit & Polyclonal & $1: 200$ \\
\hline \multicolumn{5}{|l|}{ EnVision+ } \\
\hline Mouse & DAKO, Carpinteria, California & goat & Polyclonal & no dilution \\
\hline Rabbit & DAKO, Carpinteria, California & goat & Polyclonal & no dilution \\
\hline
\end{tabular}

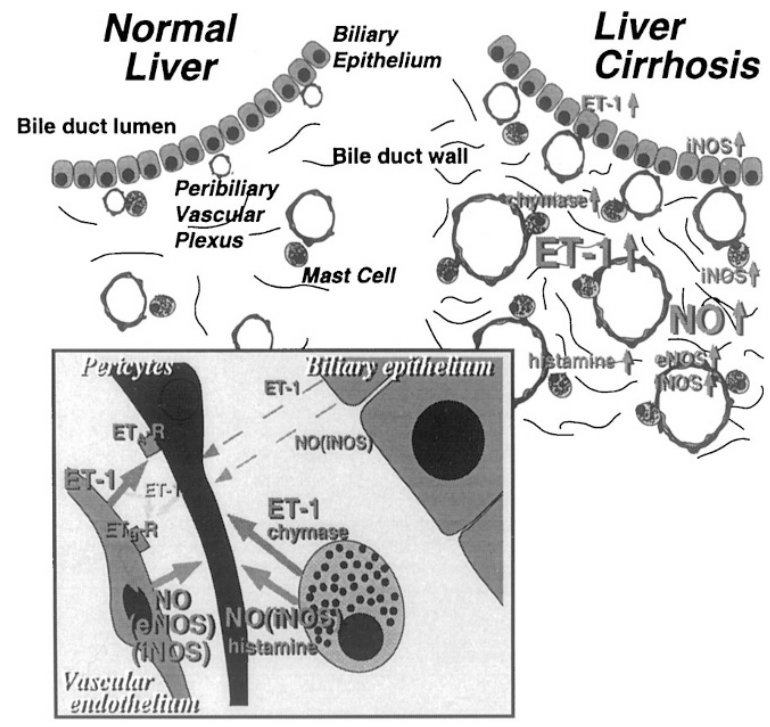

Figure 10.

Mechanism for regulation of blood flow in PVP. Microvessels of PVP are increased and dilated in liver cirrhosis. Vasoactive substances secreted locally from the cell components including MC around the biliary tree are involved in the hemodynamic regulation of PVP in normal liver and in the vascular and hyperdynamic changes of PVP in cirrhosis.

grossly. The intrahepatic large bile ducts have their own ductal wall, which consists of a hypocellular collagenous band and accompanies the peribiliary glands. The periductal tissue consists of a hypocellular and loose fibrous connective tissue around the bile duct wall. The peribiliary glands consist of the intramural and extramural glands, the intramural glands are located within the ductal wall and the extramural glands in the periductal tissue. Septal bile ducts with an external diameter over $100 \mu \mathrm{m}$ are seen in the central part of the portal tract and are branches of the intrahepatic large bile ducts. Interlobular bile ducts were classified as tubular structures in the peripheral zone of the portal tracts and had lumens of 20 to 80 $\mu \mathrm{m}$. The interlobular bile duct is subdivided into medium-sized (lumen: 40 to $80 \mu \mathrm{m}$ ) and small (lumen: 20 to $40 \mu \mathrm{m})$ ducts. Bile ductules are tubular structures in the peripheral zone of the portal tract with lumen greater than $20 \mu \mathrm{m}$.

PVP. This plexus was found around the intrahepatic large bile ducts and septal bile ducts and was categorized into inner, middle, and outer layers, according to our previous study (Kobayashi et al, 1994). The inner layers are a chain of capillaries just beneath the biliary epithelia, and the outer layers are veins and small arteries and venules in the peribiliary connective tissue. The middle layers are located in the ductal wall. Additionally, there were many small vessels and capillaries in and around the peribiliary glands, particularly the extramural glands.

Classification of Portal Tracts. The portal tracts containing small interlobular bile ducts were designated as small portal tracts; those containing mediumsized interlobular bile ducts as medium-sized portal tracts, and those containing the septal and intrahepatic large bile ducts as large portal tracts. The large portal tracts included the hepatic hilar connective tissue.

\section{Liver Tissue Specimens and Fixation}

Autopsy or surgically resected liver tissue specimens registered in our file of liver cirrhosis and normal livers were used in this study (Table 2). All liver specimens were fixed in $10 \%$ neutral buffered formalin and embedded in ordinary paraffin. In the autopsy or surgically resected specimens, the hepatic hilar regions or the large portal tracts were processed for tissue preparation in addition to the hepatic parenchyma. Seventy-one histologically normal livers were almost normal or showed nonspecific changes such as mild fatty or aganal changes. Twenty-four cases were 
hepatitis C-related chronic hepatitis. The remaining 45 cases were hepatitis C-related liver cirrhosis.

Additionally, 23 normal liver and 21 cirrhotic liver specimens, included in the formalin-fixed specimens, were also fixed in AMeX (Sato et al, 1986). That is, liver tissue specimens were fixed in acetone at $-20^{\circ} \mathrm{C}$ overnight, consecutively cleared in methyl benzoate and xylene, and embedded in paraffin. This fixation was suitable for immunoreactivity and represents a new simplified process. Conventional antibodies applicable to fresh-frozen or periodate-lysine-paraformaldehydefixed frozen sections are available for AMeX. Additionally, tissue and cellular structures are well-preserved, comparable to formalin fixation.

\section{Histologic and Immunohistochemical Study}

Histologic Study. More than 20 sections (4 $\mu \mathrm{m}-$ thick) were cut from each paraffin block, some of which were processed for routine staining including hematoxylin and eosin, reticulin, and Mallory's azan. The remaining sections were used for immunohistochemistry.

Immunohistochemistry. Immunoreactivity was performed using an avidin-biotin-peroxidase method (DAKO, Glustrup, Denmark) or EnVison+ for mouse and rabbit (DAKO). First, to prevent nonspecific binding in immunoreactivity for MC (Ruck et al, 1990), a phosphate buffer solution with elevated salt content (up to $0.5 \mathrm{M}$ ) was used for rinsing (Grube, 1980). The deparaffinized formalin-fixed sections were incubated in 0.3\% hydrogen peroxide in methanol for 30 minutes to abolish endogenous peroxidase activity. For chymase immunohistochemistry, deparaffinized AMeX-fixed sections were used. After incubation in $10 \%$ nonimmune serum, the histologic sections were incubated at $4^{\circ} \mathrm{C}$ overnight with primary mouse monoclonal antibodies against $\mathrm{MC}$ tryptase, MC chymase, CD34, ET-1, and eNOS, or with primary rabbit polyclonal antibodies against histamine, iNOS, $\mathrm{ET}_{\mathrm{A}}$ receptor, and $\mathrm{ET}_{\mathrm{B}}$ receptor with optimal dilutions as shown in Table 3. For $\mathrm{ET}_{\mathrm{A}}$ and $\mathrm{ET}_{\mathrm{B}}$ receptors immunohistochemisty, after PBS incubation, sections were treated for 45 minutes at room temperature with biotinylated secondary rabbit antibodies to sheep IgG and then with $A B C$ (Vectastain ABC kit; Vector Laboratories, Burlingame, California) for 45 minutes at room temperature. Sections for the other antigens were treated with EnVison+ for mouse or rabbit (DAKO). Peroxidase activity was visualized with a benzidine reaction. Nuclei were counterstained weakly with hematoxylin. Negative controls substituted PBS or nonimmune mouse or rabbit serum for the primary antibodies and PBS for the secondary antibodies. This procedure consistently resulted in negative immunoreactivity.

Classification of MC. According to the presence of chymase, a neutral protease of $\mathrm{MC}, \mathrm{MC}$ are largely divided into two types: $\mathrm{MC}^{\top}$ (tryptase-positive, chymase-negative $\mathrm{MC}$ ) and $\mathrm{MC}^{\mathrm{TC}}$ (tryptase-positive, chymase-positive MC) (Irani et al, 1989). The two types differ in their ultrastructure and pathophysiologic roles (Craig et al, 1988). One of the major components of $\mathrm{MC}^{\mathrm{TC}}$ is chymase (Sayama et al, 1987).
Double-Immunoreactivity of Tryptase and CD34, ASMA, iNOS, or eNOS. The relation between tryptasepositive $\mathrm{MC}$ and vascular endothelial cells or pericytes around the bile ducts and expression of iNOS or ET-1 from tryptase-positive MC was examined in five cases using double-immunoreactivity for tryptase and CD34, ASMA, iNOS, or eNOS. First, CD34, ASMA, iNOS, or eNOS was identified using the brown benzidine reaction product, and then tryptase was identified as blue using Vector blue products (Vector Laboratories). After blockage of endogenous peroxidase and incubation with $10 \%$ nonimmune goat serum, deparaffinized sections were incubated at $4^{\circ} \mathrm{C}$ overnight with primary antibody against CD34, ASMA, iNOS, or eNOS. Sections were then treated for 45 minutes at room temperature with EnVision+ for mouse or rabbit (DAKO), and then visualized by benzidine reaction. The sections were washed in running water, incubated in PBS at $98^{\circ} \mathrm{C}$ for 10 minutes, and incubated in PBS at room temperature. Next, the sections were incubated with the mouse primary monoclonal antibody against human tryptase for 2 hours at room temperature and then treated with Envision-AP ${ }^{\mathrm{TM}}$ (DAKO) for 45 minutes at room temperature. Finally, the sections were visualized by the Vector blue System (Vector Laboratories). Negative controls substituted PBS or nonimmune mouse or rabbit serum for the primary antibodies in the first and second immunoreactivity. This procedure consistently resulted in negative immunoreactivity.

\section{Counting of MC Expressing Vasoactive Substances}

Step serial sections, immunoreacted for either vasoactive substances or tryptase, were examined under a digital camera (Fuji Film, Tokyo, Japan) and the pictures were transferred to the NIH IMAGE program (National Institutes of Health, Maryland). Three to five areas around the septal bile duct and one to three areas around the intrahepatic large bile duct were chosen. MC expressing one of the vasoactive substances or tryptase were enumerated in a limited periductal area, the area of which was measured by $\mathrm{NIH}$ IMAGE. Then the density of MC per area around the bile ducts was determined.

\section{ISH}

Preparation of RNA Probes. To obtain sense and antisense RNA probes for iNOS, PCR-amplified products containing T7- and Sp6-RNA polymerase promoter were obtained using primers against iNOS (421 bp; GenBank accession number, U31511). Using these PCR-amplified products as templates, singlestranded RNA probes complementary (antisense probe) and anticomplementary (sense probe; negative control) to the corresponding gene transcripts and digoxigenin-labeling were obtained by in vitro transcription with T7- and Sp6-RNA polymerases using DIG RNA Transcription Kit ${ }^{\mathrm{TM}}$ (Boehringer Mannheim Biochemica, Indianapolis, Indiana). 
ISH. The 8 wedge-biopsy liver specimens (2 normal and 8 hepatitis $\mathrm{C}$-related cirrhotic livers) were snap frozen in OCT compound (Miles Inc., Elkhart, Indiana) and stored at $-70^{\circ} \mathrm{C}$ until use. Frozen $5 \mu \mathrm{m}$-thick sections were cut using a cryostat and mounted on poly-L-lysine coated slides. Serial frozen sections were fixed in 4\% paraformaldehyde in PBS ( $\mathrm{pH} 7.4)$ for 15 minutes, and incubated for 10 minutes at $37^{\circ} \mathrm{C}$ with $2 \mu \mathrm{g} / \mathrm{ml}$ of proteinase $\mathrm{K}$ for the proteolytic treatment. Some of these serial sections were preliminarily investigated for tryptase immunoreactivity as well as iNOS as mentioned above (see "Results"), and the sections with pertinent areas for studying MC by ISH were chosen. The MC in these suitable areas were immunoreactive for both tryptase and iNOS and easily identifiable by the neighboring structures. The serial sections to next to these pertinent sections were used for the ISH.

After postfixation for 10 minutes in $4 \%$ paraformaldehyde in PBS, the slides were rinsed in PBS and immersed in $0.2 \mathrm{~N} \mathrm{HCl}$ for 10 minutes. The sections were then thoroughly rinsed in PBS and the slides acetylated with $0.25 \%$ acetic anhydride in $0.1 \mathrm{M}$ triethanolamine for 10 minutes at room temperature. The slides were dehydrated rapidly in graded concentrations of ethanol and air-dried. They were then incubated with an ISH solution (Bioprobe Systems, Montrevil, France) containing approximately 500 $\mathrm{ng} / \mathrm{ml}$ of digoxigenin-labeled antisense or sense RNA probe in a moist chamber at $42^{\circ} \mathrm{C}$ for 16 hours. Next, sections were washed sequentially in $2 x$ SSC with $50 \%$ formamide for 30 minutes at $42^{\circ} \mathrm{C}$, in $2 \times$ SSC for 20 minutes at $42^{\circ} \mathrm{C}$, and twice in $0.2 \mathrm{x} \mathrm{SSC}$ for 20 minutes at $42^{\circ} \mathrm{C}$. After a brief wash in Tris-buffered saline (100 mM Tris- $\mathrm{HCl}, \mathrm{pH} 7.5,150 \mathrm{~mm} \mathrm{NaCl})$, sections were incubated with a normal goat serum (diluted 1:10; Vector Laboratories) for 20 minutes, then incubated with a 1:2000 dilution of mouse antidigoxigenin monoclonal antibody (BoehringerMannheim Biochemicals, Indianapolis, Indiana) in Tris-buffered saline for 1 hour. After another wash, the slides were incubated for 1 hour with goat antiimmunoglobulin-conjugated alkaline-phosphataselabeled dextran polymer (Envision-APTM, DAKO), washed twice in Tris-buffered saline for 15 minutes each time, and incubated with equalization buffer (100 $\mathrm{mm}$ Tris- $\mathrm{HCl}, \mathrm{pH}$ 9.5, $100 \mathrm{~mm} \mathrm{NaCl}, 50 \mathrm{~mm} \mathrm{MgCl}_{2}$ ) for 3 minutes. Color development was achieved by adding a freshly prepared substrate solution containing nitroblue tetrazolium salt $(450 \mu \mathrm{g} / \mathrm{ml})$ and 5-bromo-4chloro-3-indolyl phosphate toluidinium salt $(175 \mu \mathrm{g} /$ $\mathrm{ml}$ ) in equalization buffer to the slides for approximately 12 hours in a darkroom.

\section{Statistics}

Intergroup comparisons were made by the chi-square test. The correlation coefficient was determined by Fischer's exact transformation (Enoki, 1998). $p$ values less than 0.05 were regarded as significant.

\section{References}

Abelmann WH (1991). Hyperdynamic circulation. In: Okuda K and Bnehamou JP, editors. Portal hypertension: Clinical and physiological aspects. Tokyo: Springer-Verlag, 101-113.

Akiyoshi H and Terada T (1998). Mast cells, myofibroblasts and nerve terminal complexes in carbon tetrachlorideinduced cirrhotic rat livers. J Hepatol 112-119.

Alexander B (1998). The role of nitric oxide in hepatic metabolism. Nutrition 14:376-390.

Bauer M, Zhang JX, Bauer I, and Clemens MG (1994). ET-1 induced alterations of hepatic microcirculation: Sinusoidal and extrasinusoidal sites of action. Am J Physiol 267:G143-G149.

Befus D, Fujimaki H, Lee TDG, and Sweiter M (1988). Mast cell polymorphisms. Recent concepts, future directions. Dig Dis Sci 33:S16-S24.

Craig SS, Schechtner NM, and Schwartz LB (1988). Ultrastructural analysis of human T and TC mast cells identified by immunoelectron microscopy. Lab Invest 58:682-691.

Crowe SE, Kuthra GK, and Perdue MH (1997). Mast cell mediated ion transport in intestine from patients with and without inflammatory bowel disease. Gut 41:785-792.

Enoki H (1998). Statistical analysis by StatView, 5th ed., Tokyo: Kanehara Publishers.

Farrell DJ, Jones JE, Walls AF, Kelly PJ, Bennett MK, and Burt AD (1995). Intrahepatic mast cells in chronic liver diseases. Hepatology 22:1175-1181.

Feldman MJ, Morris GP, Dinda PK, and Paterson EG (1996). Mast cells mediate acid-induced augmentation of opossum esophageal blood flow via histamine and nitric oxide. Gastroenterology 110:121-128.

Foreman JC (1987). Neuropeptides and the pathogenesis of allergy. Allergy 42:1-11.

Galli SJ (1993). New concepts about the mast cell. N Engl J Med 6:91-97.

Gandhi CR, Sproat LA, and Subbotin VM (1996). Increased hepatic endothelin-1 levels and endothelin receptor density in cirrhotic rats. Life Science 58:55-62.

Gondo K, Ueno T, Sakamoto M, Sakisaka S, Sata M, and Tanikawa K (1993). The endothelin-1 binding site in rat liver tissue: Light- and electron-microscopic autoradiographic studies. Gastroenterology 104:1745-1749.

Grube D (1980). Immunoreactivities of gastrin (G-) cells. II. Non-specific binding of immunoglobulins to G-cells by ionic interactions. Histochemistry 66:149-167.

Housset C, Carayon A, Housset B, Legendre C, Hannoun L, and Pououn R (1993). Endothelin-1 secretion by human gallbladder epithelial cells in primary culture. Lab Invest 69:750-755.

Irani AA, Bradford TR, Kepley CL, Schechter NM, and Schwartz LB (1989). Detection of MCT and MCTC types of human mast cells by immunohistochemistry using new monoclonal anti-tryptase and anti-chymase antibodies. $\mathrm{J}$ Histochem Cytochem 37:1509-1515.

Kobayashi K, Nakanuma Y, and Matsui O (1994). Intrahepatic peribiliary vascular plexus in various hepatobiliary diseases: A histological study. Hum Pathol 25:940-946.

Laffi $G$ and Marra F (1999). Complications of cirrhosis: Is endothelium guilty? J Hepatol 30:532-535. 
Lancaster JR (1994). Stimulation of the diffusion and reaction of endogenously produced nitric oxide. Proc Natl Acad Sci 91:8137-8147.

Leivas A, Jimenez W, Bruix J, Boix L, Bosch J, Arroyo V, Rivera F, and Rodes J (1998). Gene expression of endothelin-1 and $E T(A)$ and $E T(B)$ receptors in human cirrhosis: Relationship with hepatic hemodynamics. J Vas Res 35:186-193.

Lewis RS, Tamir S, Tannenbaum SR, and Deen WM (1995). Kinetic analysis of the fate of nitric oxide synthase by macrophage in vitro. J Biol Chem 270:29350-29355.

Lopez-Talavera JC, Cadelina G, Olchowski J, Merrill W, and Groszman RJ (1996). Thalidomide inhibits tumor necrosis factor, decreases nitric oxide synthesis, and ameliorates the hyperdynamic circulatory syndrome in portal-hypertensive rats. Hepatology 23:1616-1621.

Luscher TF, Tanner FC, Tschudi MR, and Noll G (1993). Endothelial dysfunction in coronary artery disease. Annu Rev Med 44:395-418.

Martini PY, Xu DL, Niederbergen M, Weigert A, Tsai P, St John J, and Schrier RW (1996). Upregulation of endothelial constitutive NOS: A major role in the increased NO production in cirrhotic rats. Am J Physiol 270:F494-499.

Michielsen PP and Pelckmans PA (1994). Haemodynamic changes in portal hypertension: New insights in the pathogenesis and clinical implications. Acta Gastroenterol Belg 57:194-205

Morris SM and Billian TR (1994). New insights into the regulation of inducible nitric oxide synthesis. Am J Physiol 266:E829-839.

Nakanuma Y, Hoso M, Sanzen T, and Sasaki M (1997). Microstructure and development of the normal and pathologic biliary tract in humans, including blood supply. Microscopy Res Tech 38:552-570.

Okunishi H, Miyazaki M, and Toda N (1984). Evidence for a putatively new angiotensin II-generating enzyme in the vascular wall. J Hypertens 2:277-284.

Omori M, Omori N, Evarts RP, Teramoto T, and Thorgeirsson SS (1997). Coexpression of flt-3 ligand/flt-3 and SCF/c-kit signal transduction system in bile-duct-ligated $\mathrm{SI}$ and $\mathrm{W}$ mice. Am J Pathol 150:1179-1187.

Pinzani M, Milani S, de Franco R, Grappone C, Caligiuri A, Gentilin A, Tosti-Guerra C, Maggi M, Failli P, Ruocco C, and Gentilini P (1996). Endothelin-1 is overexpressed in human cirrhotic liver and exerts multiple effects on activated hepatic stellate cells. Gastroenterol 110:534-548.

Reilly FD, Dimlich RV, Cilento EV, and MuCuskey RS (1983). Hepatic microvascular regulatory mechanisms. III. Amierngic mechanisms as related to mast cells. Int $\mathrm{J}$ Microcirc Clin Exp 2:61-73.

Rockey DC, Fouassir L, Chung JJ, Carayan A, Vallee P, Rey C, and Housset C (1998). Cellular localization of endothelin-1 and increased production in liver injury in the rat: Potential for autocrine and paracrine effects on stellate cells. Hepatology 27:472-480.

Ruck P, Horny HP, and Kaiserling E (1990). Immunoreactivity of human tissue mast cells: Nonspecific binding of primary antibodies against regulatory peptides by ionic linkage. $\mathrm{J}$ Histochem Cytochem 38:859-867.
Sato Y, Mukai K, Watanabe S, Goto M, and Shimosato Y (1986). The AMeX method: A simplified technique of tissue processing and paraffin embedding with improved preservation of antigens for immuno-staining. Am J Pathol 125:431-435.

Sayama S, lozzo RV, Lazarus GS, and Schechter NM (1987). Human skin chymotrypsin-like proteinase chymase. Subcellular localization to mast cell granules and interaction with heparin and other glycosaminoglycans. Biol Chem 262: 6808-6815.

Schmidt HW and Walter U (1994). NO at work. Cell 78:719-725.

Schrier RW, Arroyo Y, Bernardi M, Epstain M, Henriksen JH, and Rodes J (1988). Peripheral arterial vasodilatation hypothesis: A proposal for the initiation of renal sodium and retention in cirrhosis. Hepatology 8:1151-1157.

Shibayama $Y$ (1998). Regulation of hemodynamics of the liver. In: Toda G, Oda M, Kiyosawa K, Tsubouchi H, and Nakanuma Y, editors. Hepatology. Basic Science. Tokyo: Igaku Shoin, 349-355 (Japanese).

Sogni P, Moreau R, Gadano A, and Lebrec D (1995). The role of nitric oxide in the hyperdynamic circulatory syndrome associated with portal hypertension. J Hepatol 23:218-224.

Sogni P, Smith APL, Gadano A, Lebrec D, and Higenbottam TW (1997). Induction of nitric oxide synthase II does not account for excess vascular nitric oxide production in experimental cirrhosis. J Hepatol 26:1120-1127.

Suzuki H, Miura S, Liu YY, Tsuchiya M, and Ishii H (1995). Substance $P$ induces degranulation of mast cells and leukocyte adhesion to venular endothelium. Peptides 16:1447-1452.

Uchida Y, Ninomiya H, Sakamoto T, Lee JY, Endo T, Nomura A, Hasegawa S, and Hirata F (1992). ET-1 released histamine from guinea pig pulmonary but not peritoneal mast cells. Biochem Biophys Res Commun 189:1196-1201.

Vallance P and Moncada S (1991). Hyperdynamic circulation in cirrhosis: A role for nitric oxide? Lancet 337:776-778.

Wallace JL, McKnight GW, and Gefus AD (1992). Capsaicininduced hyperemia in the stomach: Possible contribution of mast cells. Am J Physiol 263:G209-G214.

Walls AF, Jones DB, Williams JH, Church MK, and Holgate ST (1990). Immunohistochemical identification of mast cells in formaldehyde-fixed tissue using monoclonal antibodies specific for tryptase. J Pathol 162:119-126.

Weidner N and Austen KF (1990). Evidence of morphologic diversity of human mat cells. An ultrastructural study of mast cells from multiple body sites. Lab Invest 63:63-72.

Weidner N and Austen KF (1991). Ultrastructural and immunohistochemical characterization of normal mast cells at multiple body sites. J Invest Dermatol 96:26S-31S.

Yamashiro M, Kouda W, Kono N, Tsuneyama K, Matsui O, and Nakanuma $Y$ (1998). Distribution of intrahepatic mast cells in various hepatobiliary disorders: An immunohistochemical study. Virchow Archiv 433:471-479.

Yanagisawa M (1994). The endothelin system. A new target for therapeutic intervention. Circulation 89:1320-1322. 